\title{
FROM SCRIPT TO PRINT: EDITING THE ANTIDOTARY IN GLASGOW, UNIVERSITY LIBRARY, MS HUNTER 513 (FF. 37v-96v)
}

\author{
Teresa Marqués-Aguado, Universidad de Murcia \\ Email: tmarques@um.es
}

\begin{abstract}
This article presents the procedure followed to carry out the edition of the Antidotary held in Glasgow, University Library, MS Hunter 513. For the purpose, the treatise is first briefly described, along with its peculiarities; then, the main difficulties encountered during the transcription process are outlined. Finally, the features of the printed edition (including layout, use of critical apparatuses or of a glossary, etc.) are discussed.
\end{abstract}

Keywords: Middle English, editing, Antidotary, palaeography, scientific texts.

Título en español: De la escritura a la edición: edición del Antidotario en el manuscrito Glasgow, University Library, Hunter 513 (fols. 37v-96v)

Resumen: Este artículo presenta el procedimiento seguido para realizar la edición del Antidotario que se encuentra en el manuscrito Hunter 513 de la Colección Hunteriana de la Universidad de Glasgow. Para ello, tras describir brevemente el tratado y sus peculiaridades, se señalan las principales dificultades encontradas durante el proceso de transcripción. Por último, se especifican las características de la edición impresa, tales como el formato, la utilización de aparatos críticos o de un glosario, etc.

Palabras clave: Inglés medio, edición, Antidotario, paleografía, textos científicos.

\section{INTRODUCTION}

Textual editing has been a paramount concern in textual studies - especially from the nineteenth century onward-, inasmuch as it invariably entails an interpretation of the text on the part of the editor, as suggested by HANNA (1992: 110) or MACHAN (1992: 1). Editions are commonly organised in a cline or continuum in which diplomatic editions are at one end and critical editions at the opposite end, whereas "most modern editions are rightly a compromise between them" (HuDSON 1977: 39).

In recent times, editing has undergone several key changes, two of which should be highlighted for the purposes of this article. On the one hand, the edition and subsequent research on texts that belong to fields of knowledge other than literature (such as science) have progressively gained ground over the last decades. On the other hand, digital editions allow for a wider (and more rapid) dissemination of knowledge. It is evident that this

Date of reception: 31 May 2012

Date of acceptance: 26 October 2012 
changing environment has inevitably had an impact on the format and the possibilities offered to any editor.

In the light of this situation, the work presented in this article is linked to a series of research projects at the University of Málaga (Spain) which seek to transcribe and edit (both online and in print) Middle English medical texts (see those by MirANDA-GARCíA and González Fernández-Corujedo [2011] or Calle-Martín and Miranda-García [2011]), hence constituting a good example of the situation just depicted. Besides editing, the common aim of these projects is that of compiling (and progressively enlarging) a corpus of unedited Middle English scientific prose, which is also lemmatised and tagged. At the moment, the corpus amounts to roughly 700,000 items and comprises more than twenty texts whose areas of provenance are diverse and which are held in five different repositories. $^{2}$ These features make this corpus representative within the domain of scientific (and particularly medical) Middle English language.

In relation to the compilation of corpora based on historical texts, LASS (2004: 31) has discussed that editions cannot be readily trusted given that "an emended text is a falsehood, if as so often happens it's taken unreflectively as a witness for a past language state". As a consequence, "the ideal model for a corpus or any presentation of a historical text is an archaeological site or a crime-scene: no contamination, explicit stratigraphy, and an immaculately preserved chain of custody" (LAss 2004: 46). This is the reason why The Corpus of Late Middle English Scientific Prose is based on transcriptions, rather than on published editions of these texts (whenever available): studies and data on the language of the period will be more trustworthy if they come from transcribed texts, rather than from editions which may follow a variety of editorial policies.

Accordingly, the present article is structured into three sections. First, the text under scrutiny is briefly described, along with the remaining extant copies. Second, the procedure and conventions followed in the transcription of the text are outlined, along with the major difficulties encountered. The corresponding electronic edition is also presented. Third, the conventions of the printed edition are put forward and set in contrast to those followed in the online edition. Finally, the references close the article.

\section{THE TEXT}

The editorial process that will be scrutinised focuses on one of the witnesses of the textual tradition of the Antidotary; namely, the one held in Glasgow, University Library, MS Hunter 513 (ff. 37v-96v). ${ }^{3}$ This copy will be referred to as H513 hereafter. This mid-fifteenth-century witness was initially catalogued as an anonymous text (Young and AITKEN 1908: 421; Cross 2004: 35), but recent research (MARQUÉS-AgUADo 2008: 58-64) has proved that this is a composite text inasmuch as it blends parts of two key medieval surgical treatises: ff. $37 \mathrm{v}-88 \mathrm{v}$ contain part of Mondeville's antidotary (the fifth chapter in his surgical work), whereas ff. $88 \mathrm{v}-96 \mathrm{v}$ present the second doctrine in the seventh book in

\footnotetext{
2 These are: Glasgow, University Library; London, British Library and Wellcome Library; Oxford, Bodleian Library; and Manchester, John Rylands Library.

3 The rest of the manuscript contains other three medical texts, on ophthalmology and zodiacal influence.
} 
Guy de Chauliac's surgery. Both Mondeville and Chauliac were reputed French surgeons at their time (thirteenth and fourteenth centuries).

Besides H513, other five witnesses of the same treatise have been identified: Glasgow, University Library, MS Hunter 95 (ff. 156r-184r) [henceforth H95]; London, British Library, MSS Sloane 2463 (ff. 153v-193v) and Sloane 3486 (ff. 3-18); Oxford, Bodleian Library, MSAshmole 1468 (ff. 139-171); and New York, Academy of Medicine, MS 13 (ff. 152-188v).

It must also be stressed that this composite Antidotary does not appear in isolation in these six witnesses, but rather as part of a longer text, whose incipit reads "Here beginneth a treatise of Ipocras Galen Lucien? Henricus de Amondavilla"4, registered in VoIGTS and KURTZ's electronic catalogue (2000). This longer treatise normally includes a text commonly referred to as the Book of Operation, which precedes the Antidotary almost systematically, the only exception being MS Sloane 3486, where the order is curiously reversed. The fact that $\mathrm{H} 513$ has been extracted from this original, longer treatise and functions independently in this manuscript implies that it is also a text in its own right, although this is a slippery concept when dealing with medieval works. ${ }^{5}$ This tendency has been remarked by other scholars, such as MäKINEN (2006: 10), for whom "medieval texts are also prone to fragmentation: a passage that appears on its own, as a separate entity in a manuscript, may have been extracted from a longer text".

\section{TRANSCRIPTION, LEMMATISATION AND TAGGING, AND ELECTRONIC EDITION}

\subsection{Transcription}

Transcribing is an essential step for the subsequent task of editing, whether electronically or in print. Moreover, given that this treatise belongs to a corpus compiled following a series of requirements, the accuracy of the transcription with regard to the original in the manuscript has proved to be essential.

The transcription of H513 was carried out using the manuscript itself, as well as the corresponding digitised images, which were of particular help to revise and check uncertain readings. Easy as this might seem, especially when having such a wide array of sources at hand, this process faced several difficulties. First, minims are not fully distinguished, a recurrent problem in some medieval scripts, such as Anglicana. This situation is particularly true in H513, the script of which can be catalogued as Anglicana for the most part, though with some letter-forms taken from Secretary script. Aware of this potential confusion, the scribe of most of H513 employed two different mechanisms to partially solve ambiguity:

\footnotetext{
4 Though the reading is unclear according to the question mark inserted in VoIGTS and KURTZ's catalogue (2000), the witness in H95 clearly reads 'Auícen' (f. 84r).

5 Yet, the scribe betrayed the fragmentary nature of $\mathrm{H} 513$ by retaining references to chapters, ideas, concepts, etc. that had been presumably dealt with in other sections of the longer treatise but which had been suppressed in H513 (MARQUÉS-AgUADo 2008: 67).
} 
in some cases, acute accents were added over $<\mathrm{i}>$; in some others, $<$ w $>$ was used in the place of $<\mathrm{u}>$, as shown in Figs. 1 and 2, respectively: ${ }^{6}$

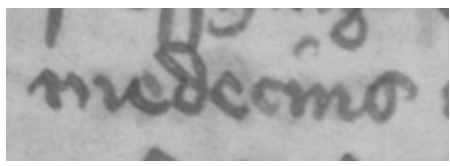

Fig. 1. 'medecíns' (f. 37v).

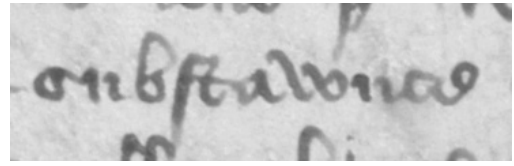

Fig. 2. 'substawnce' (f. 57r).

However, some words such as present-day English 'betony' or 'colophony' present further complications when transcribing, since the use of confusing minims cannot be solved either by resorting to the presence of an acute accent (since it is not employed) or else by discarding unattested spellings in a reference work such as the Middle English Dictionary (http://quod.lib.umich.edu/m/med/), where both $<$ colofonie $>$ and $<$ colofoine $>$ are registered. Fig. 3 shows one such example. The solution adopted has been to transcribe it according to the most frequent spelling in H513 (i.e. 'colofonie'), which was found only after checking all the expanded spellings:

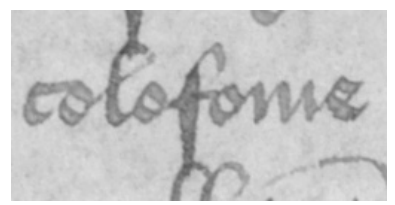

Fig. 3. 'colofonie' or 'colofoine'? (f. 95r).

Second, the extensive use of abbreviations, which had to be expanded and duly italicised because of the difficulties of putting them into typescript, paves the ground for a variety of complications. ${ }^{7}$ Some of the abbreviations can be read in different ways, as in Fig. 4, where the special sign indicating the plural inflection of the noun may be expanded to -es, -is or $-y s{ }^{8}$ Again, the most frequent expanded form for each word has been the one preferred. On other occasions, one brevigraph may be employed to represent altogether different abbreviations, as shown in Figs. 5 and 6, where the same brevigraph stands for two different sequences of letters: <er $>$ in the former, and $<$ re $>$ in the latter. In turn, the same abbreviation may be represented by different brevigraphs depending on the preceding letter-form, as shown in Figs. 7 and 8, where the abbreviation $<$ er $>$ is given under other two brevigraphs:

\footnotetext{
${ }_{6} \quad$ Several hands contributed to rendering H513. The main one copies most of the text (ff. 37v-94v), while the remaining folios are copied by a hand which shows more Secretary features (an example of which is available in Fig. 3). Yet, both use diacritic over $<i>$ to prevent ambiguity due to minim confusion. A third hand may be claimed to have deployed chapter headings and litterae notabiliores.

7 As a matter of fact, PARKES simply used an apostrophe in the place of such strokes in his transcriptions (1969: $\mathrm{xxx}$ ) so as not to run the risk of introducing spelling forms alien to the system followed by the scribe.

8 See also Voigts (1989: 94).
} 


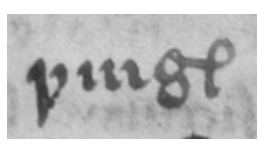

Fig. 4. 'pinges' (f. 42v).

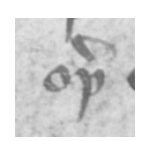

Fig. 5. 'oper' (f. 39r).

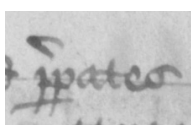

Fig. 6. 'preparates' (f. 47r).

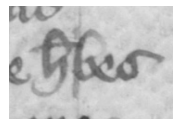

Fig. 7. 'herbes' (f. 75r).

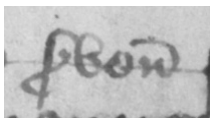

Fig. 8. 'serven' (f. 53r).

Abbreviations concerning apothecaries' weights and measures have been rather difficult to transcribe, especially when appearing in a series or when combined with numbers (see Fig. 9). ${ }^{9}$ Nevertheless, other witnesses (especially H95) have been quite helpful in discerning these aspects, as explained in section 4 :

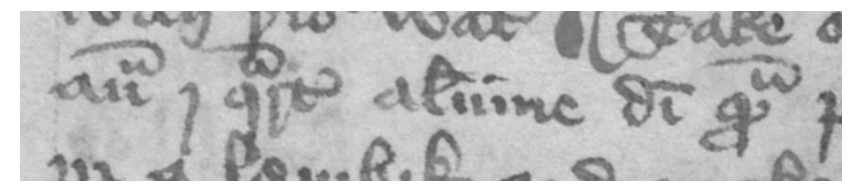

Fig. 9. 'ana 1 quarter alumme dim quart' (f. 92v).

As for superscript characters (which sometimes feature abbreviations), they have been retained when referring to ordinals or when encountered with abbreviations of weights, as this has been felt to be a common practice in present-day English, too, especially in the case of ordinals. However, superscript characters in words such as 'pe' or 'pu' have not been italicised because italicisation is reserved to render missing letters, hence the convenience of transcribing $\left\langle\mathrm{w}^{\mathrm{t}}\right\rangle$ as ' $w i t h$ '.

On another note, it should also be stressed that the different letter-forms - for instance, the different types of $<\mathrm{a}>$ (that is, the Anglicana two-lobbed letter-form and the rounded Secretary) or the somehow positionally-conditioned $<\mathrm{s}>$ letter-forms (initial or final Anglicana sigma $<\mathrm{s}>$, as opposed to the initial or medial long $\langle\mathrm{s}>$ ) - have not been preserved, because the letter-forms have been interpreted graphemically rather than graphetically. Yet, characters such as $\left.\langle\dot{\mathrm{y}}\rangle,<_{3}\right\rangle$ and $\langle\mathrm{p}>$ have not been replaced with $<\mathrm{y}\rangle,\langle\mathrm{gh}\rangle$ or $<$ th $>$, but retained, as shown in Figs. 10 to 12:

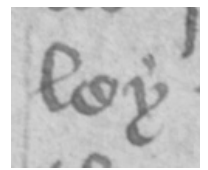

Fig. 10. 'lèy' (f. 75v).

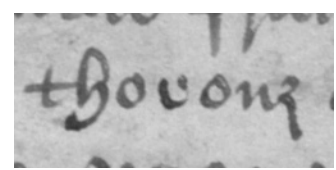

Fig. 11. 'thorou3' (f. 59r).

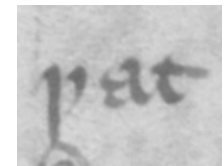

Fig. 12. 'pat' (f. 65r).

\footnotetext{
9 See Voigts (1989: 101) for a more comprehensive list of abbreviations used in scientific texts.
} 


\subsection{Lemmatisation and tagging}

Once the transcription was finished, this was duplicated and saved as a separate file, where some changes were implemented with a view to facilitating the lemmatisation and tagging of the text. In this file, word-division was standardised, and the resulting file was then pasted onto an Excel spreadsheet, where each word was allotted one row. These words were then lemmatised (using for this purpose the entries from the Middle English Dictionary) and tagged. These tags comprise information such as word-class and accidence (tense, grade, number, etc.), along with the meaning in present-day English, ${ }^{10}$ and the reference to the folio (including recto and verso) and line-span (marked every five lines), as shown in Fig. 13:

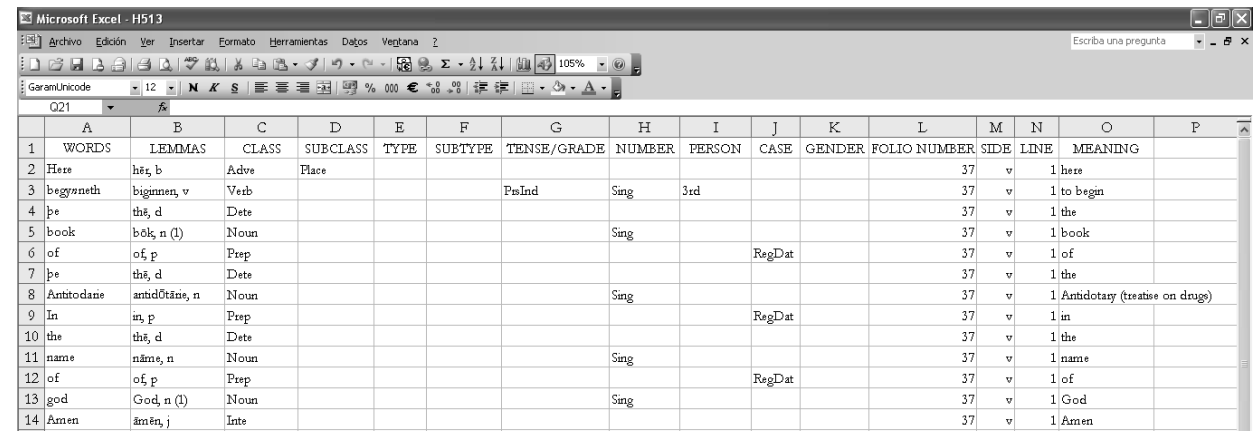

Fig. 13. Sample of the Excel file containing lemmatisation and tagging.

\subsection{Electronic edition}

As opposed to the printed edition (see section 4), most features have been maintained in the online edition (available at http://hunter.uma.es/) as they stand in the manuscript, given that this is a diplomatic edition. Firstly, the manuscript lineation and layout are retained without changes, although the text has been numbered on the left at intervals of five lines, and the number of the folio has been added to the left of the first line. Secondly, infilled letters and colours (i.e. red and blue) in chapter-initial letters, chapter headings, etc., are preserved, too. Thirdly, the repertoire of punctuation marks (including tildes and line-fillers) is kept unchanged, and so is word-division: double hyphens used to split words between two lines are reproduced from the manuscript, and when words split between two lines without any mark, no hyphen is added. Likewise, when two words run together, they are not split, although this may contradict present-day English usage. Finally, scribal errors (including misspellings and dittographies, among others) are, obviously, not emended, a task that is reserved for the printed edition. Scribal corrections are also reproduced, as with expunction (Fig. 14), and scribal insertions are added (as they are part of the text under study) and enclosed in downward half-square brackets ( \ulcorner\urcorner$)$, as in Fig. 15:

\footnotetext{
10 Meanings were taken from the Middle English Dictionary, but in the event of words not registered in this
} work, the Oxford English Dictionary (SIMPSON and WEINER 2004) was also checked. 


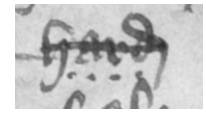

Fig. 14. (f. 50r)

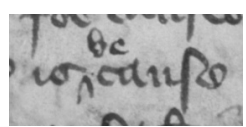

Fig. 15. 'is ${ }_{\wedge} \Gamma \mathrm{be}_{\rceil}$cause' (f. $\left.81 \mathrm{v}\right)$

Two changes may be noted in the transcription, though, and these are mirrored in the electronic edition, too. On the one hand, capital $<\mathrm{I} / \mathrm{J}>$ has been transcribed as $<\mathrm{I}>$ throughout. On the other, marginal annotations are provided as footnotes in the transcription, the reference number being placed in the line closest to the place where they are located in the manuscript (in the inner or outer margin). The electronic edition, however, shows them as pop-up windows when mousing over the digitised images. An example is provided in Fig. 16:

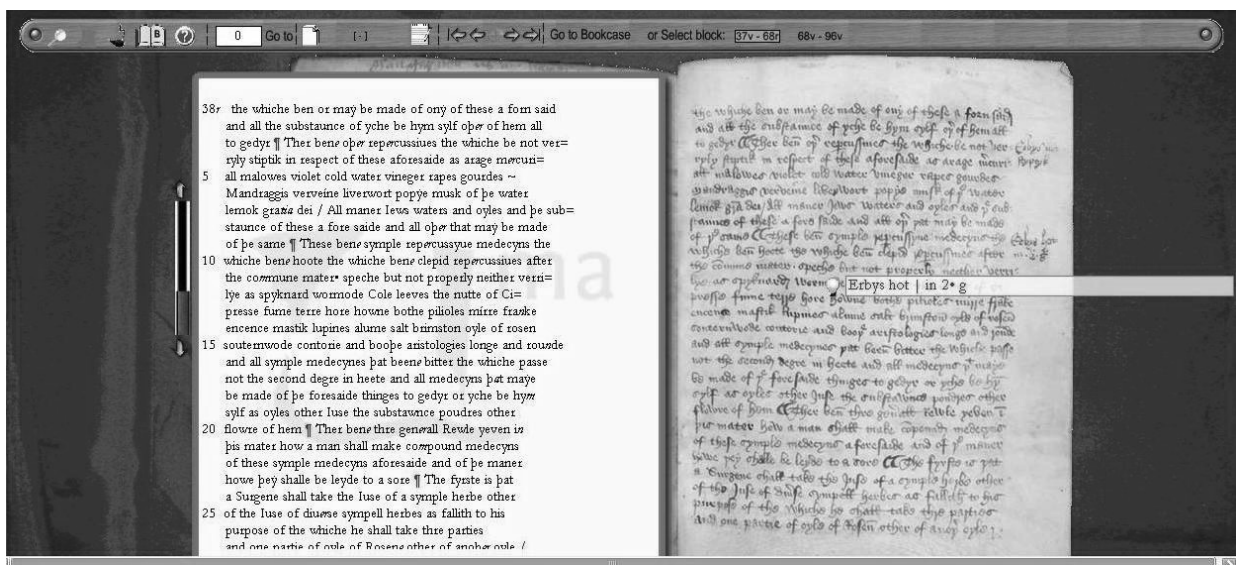

Fig. 16. Sample of the electronic edition, along with the digitised image

\section{THE PRINTED EDITION}

In the printed edition some modifications have been undertaken, and they all "bear the influence of the editor in everything from layout to punctuation to the actual words on the page" (MACHAN 1992: 1). It is important to note that, as HANNA has pointed out (1992: 122), "one can thus visualize, not An Edition, but a range of use- or interest-driven possible editions".

In general terms, the proposed edition is neither strictly diplomatic nor fully critical, but rather half-way between the two. PetTi (1977: 34) has described this as "a useful compromise $[\ldots]$ which provides nearly all that a diplomatic transcription would, but in a more continuous process. It gives scope for editorial interpretation while clearly indicating where this has been carried out". Bearing in mind this approach, some changes have been introduced in terms of layout, punctuation, scribal corrections and editorial emendations, plus the addition of Explanatory Notes that delve into particularly interesting lexical, textual and historical aspects of the text. 
Before dealing with these changes, we must refer to the relationship that H513 holds with another witness of this text (listed in section 2), since this will shed light on the editorial emendations implemented. When introducing changes based on other witnesses, H95 has been employed by and large owing to the fact that it seems to be a better copy of the text, since many omissions and errors in H513 are deployed correctly in H95. For the Chauliac section (ff. 88v-96v), OGDEN's 1971 edition has also been checked, since this is the only published edition on (at least, part of) the text under study. In these cases, the reading offered by $\mathrm{H} 95$ has been preferred to that in Ogden's work, not because it is considered to be more authoritative in any sense but rather on account of two reasons: first, H95 has been systematically used throughout the edition when emendation has been required; second, H95 is closer to H513 in its wording, syntactic constructions, etc. In turn, if an emendation is extracted only from Ogden's edition of Chauliac, then it stands on its own and is marked as such. Nonetheless, no systematic collation of these texts has been attempted, to the extent that additional information included in either H95 or Ogden's edition (i.e. background information which is not strictly necessary for a correct understanding of H513 as it stands in the manuscript) has not been inserted in the edition, but confined to the Explanatory Notes.

\subsection{Layout}

Several aspects are worth mentioning as regards the layout of the printed edition. First, paragraphing and linear arrangement are fully editorial, although the original layout of the text is reflected by way of $\langle>>$ (indicating every five lines in the manuscript) and $<\|>$ (indicating a page break). The latter is accompanied by the folio number in the outer margin. Additionally, the lineation of the edition itself is provided every five lines in the outer margin in order to facilitate references.

Second, spelling has been regularised to fit upper- and lower-case letters to present-day English usage. For example, capital letters that are not sentence-initial or do not indicate a proper name are rendered in lower-case letters and vice versa.

Finally, word-division has been standardised without making comments on the individual words that have been modified, unless the change implies the splitting up of words that run together in H513; in this case, a note has been added in the second apparatus (see section 4.5). ${ }^{11}$ Accordingly, words that run together (such as 'tapsiapes milui' [f. 68v]) but should be separated ('tapsia pes milui'), have been split to fit presentday English usage. Similarly, compounds such as 'thre-cornerd' (f. 90v) have been joined, following QUIRK ET $A L$.'s indications on the use of hyphens with compounds (1992: 1613-1614).

\footnotetext{
11 Since the transcription and the online edition preserve the original word-division, there is no need to highlight each change.
} 


\subsection{Punctuation}

Punctuation has been modernised following a previous analysis of the original marks and the functions that they fulfil in H513, which allowed for the selection of functional equivalents in present-day English (MARQUÉS-AGUADO 2009). ${ }^{12}$

When looking for these modern equivalents, lemmatisation and tagging have proved to be very useful, since these tasks have facilitated the understanding of the text. At any rate, modernising punctuation inevitably implies an interpretation on the part of the editor that might not have been intended by the scribe of the text, let alone the author (MoORMAN 1975: 85). The fact that present-day and Middle English prose are so different is the reason why some scholars, such as HUDSON (1977: 50-51), do not agree with this practice of modernising, although it certainly contributes to bringing the text closer to the reader and may, therefore, be a concern when editing critically.

Two conventions of the printed edition of H513 that should be highlighted are the following ones: a) the systematic deletion of the tilde $(\langle\sim\rangle)$, which works in the manuscript as a kind of line-filler to adjust the text to the frame; and $b$ ) the rendering of titles of works cited (such as those by Avicenna, Galen and other scholars) in inverted commas, thus avoiding the current practice of italicising them in order to prevent ambiguity with the characters in italics standing for abbreviations.

\subsection{Scribal corrections and insertions}

Scribal corrections have been introduced in the main text and marked with upward half-square brackets $L\lrcorner$, excepting the excerpts where material has been deleted, in which case no trace is left. In either situation, the method used by the scribe (expunction, alteration, etc.) is collected in the apparatus containing marginalia (see section 4.5), where the precorrection reading is offered. This decision is based on the scantiness of these corrections (which would make the use of another apparatus for this purpose almost redundant), and on the fact that neither marginal notes nor scribal emendations are editorial.

Similarly, scribal insertions (marked in the manuscript by means of the caret and located above the baseline) have been collected in the text in downward half-square brackets $\Gamma\urcorner$ (as with the transcription and the online edition; see section 3.3) and also gathered in the first apparatus.

\subsection{Editorial changes}

Editorial emendations comprise corrections (for example, misspellings or additions), which have been implemented by resorting either to other witnesses or to the text itself (in terms of textual cohesion and coherence). The former are marked by means of square brackets [ ], whereas the latter are enclosed in braces \{\} . In the event of editorial omissions from the base text (e.g. dittographies, repeated passages, etc.), no mark has been added

12 On similar studies proposing functional equivalents for English historical punctuation, see CALLE-MARTíN and Miranda-García (2008), Esteban-Segura (2009) and Marqués-Aguado (2007), among others. 
to the edition; instead, these changes are referred to in the second critical apparatus (see section 4.5) and, if necessary, a comment is added in the Explanatory Notes.

In the event of blottings or other types of damage on the writing surface - or of trimming in the case of marginal notes - that prevent the legibility of certain words (or parts of words), the reconstruction of such words has been achieved for the most part. These reconstructions are marked in the edition by means of diamond brackets $<>$.

\subsection{Apparatuses}

The edition is supplemented by three apparatuses, each of which is devoted to a particular aspect of editorial intervention. The first one comprises marginalia. These notes are also subjected to the editorial conventions explained above (word-division, layout, italicisation of abbreviations, etc.). The hands responsible are indicated in parentheses if different from the main hand. Indeed, H513 was heavily annotated, as up to five hands have been identified in the marginalia, whose common function is to highlight particularly important pieces of information, especially medical and technical.

The second apparatus collects the original readings of $\mathrm{H} 513$ where editorial emendations have been introduced, including the reference to the source for this emendation (if any), that is, H95 in most cases, but also Ogden's edition for ff. 88v-96v (see section 4). These emendations are also subjected to the editorial conventions referred above.

When dealing with textual errors, two approaches can be followed (Moorman 1975: 56-57): either to correct them, hence restoring the text to the state in which it was presumably delivered to the scribe; or else to respect the manuscript readings to the extent that no corrections are imposed. Yet, a middle course has been followed: whenever it has not been possible to justify a manuscript reading, then it has been emended. The notation used is square brackets [ ] for readings taken from other manuscripts and braces \{\} for fully editorial emendations not based on other witnesses (see section 4.4). Yet whenever possible, these have been modelled on "the scribe's linguistic habits", as advised by LuCAS (1998: 173).

The third apparatus is devoted to the Explanatory Notes, which provide commentaries on the conceptual, linguistic and textual tradition of the text; discuss unclear passages or emendations; and present suggestions. This apparatus has "the all-important purpose of making the edited text more easily accessible and comprehensible" (KEISER 1998: 122). These include information on the textual, lexical, historical and literary background of the text, following EDWARDS and MoFFAT's taxonomy (1998: 220).

\subsection{Glossary}

The use of a glossary at the end of an edited Middle English text has become a commonplace, and this is all the more useful when dealing with specialised texts such as the one under study. One of the major decisions concerning the glossary is the scope to be adopted, that is, whether to present a general or a specialised one. In this line, Moorman (1975: 89) suggests that the nature of a glossary depends on its prospective users, although 
the text-type also plays a major role in this decision, as put forward by MoFFAT (1998: 239).

In view of the type of text, a glossary containing at least specialised terms is essential so as to understand the nature of the text. In order to present the glossary, the lemmatised file explained in section 3.2 has been used as input for Text Search Engine (MIRANDAGARCÍA and GARRIDO-GARRIDO 2011), a software tool especially designed to extract lexical information from texts annotated complying with the model followed by this text. Accordingly, the glossary is arranged as follows. The lemmas or entries are those taken from the Middle English Dictionary. These are followed by grammatical information on the word-class and by the meaning(s). These are drawn from the same source (or from the Oxford English Dictionary in the case of words not registered in the Middle English Dictionary; see footnote 11) and arranged (if there are two or more meanings) in descending order of frequency according to the information provided by the text. Finally, the various spellings associated to each lemma are given, along with their frequencies.

\section{REFERENCES}

Calle-Martín, J. and A. Miranda-García. 2008. "The Punctuation System of Elizabethan Legal Documents: The Case of G.U.L. MS Hunter 3 (S. 1. 3.)”. Review of English Studies 59, 3: 356-378.

. 2012. The Middle English Version of De Viribus Herbarum (GUL MS Hunter 497, ff. 1r-92r). Edition and Philological Study. Vol. 2 of Middle English Texts Series. Bern/ Berlin/ Bruxelles/ Frankfurt am Main/ New York/ Oxford/ Wien: Peter Lang.

Cross, R. A. 2004. A Handlist of Manuscripts containing English in the Hunterian Collection Glasgow University Library. Glasgow: Glasgow University Library.

Edwards, A. S. G. and D. Moffat. 1998. “Annotation”. A Guide to Editing Middle English. Eds. V. P. McCARren and D. Moffat. Ann Arbor: The University of Michigan Press. 217-236.

Esteban-Segura, L. 2009. "Punctuation Practice in MS G.U.L. Hunter 509”. Textual Healing: Studies in Medieval English Medical, Scientific and Technical Texts. Eds. J. J. Díaz Vera and R. Caballero Rodríguez. Bern/ New York: Peter Lang. 93-107.

Hanna, R. 1992. "Producing Manuscripts and Editions". Crux and Controversy in Middle English Textual Criticism. Eds. A. J. Minnis and C. Brewer. Cambridge: D.S. Brewer. 109-130.

Hudson, A. 1977. "Middle English". Editing Medieval Texts: English, French and Latin Written in England. Papers given at the Twelfth Annual Conference on Editorial Problems. Ed. A. G. RigG. New York/ London: Garland. 34-57. 
KeISER, G. 1998. "Editing Scientific and Practical Writing”. A Guide to Editing Middle English. Eds. V. P. McCARren and D. Moffat. Ann Arbor: The University of Michigan Press. 109-122.

KURATH, H. et al., eds. 1956-2001. Middle English Dictionary. Ann Arbor: University of Michigan Press. Online version in F. MCSPARran et al., 2001-. Middle English Compendium, University of Michigan Digital Library Production Service. 29 March $2012<$ http://quod.lib.umich.edu/m/med/>.

Lass, R. 2004. "Ut Custodiant Literas: Editions, Corpora and Witnesshood". Methods and Data in English Historical Dialectology. Eds. M. Dossena and R. LAss. Bern/ Berlin/ Bruxelles/ Frankfurt am Main/ New York/ Oxford/ Wien: Peter Lang. 21-48.

LuCAS, P. J. 1998. "The Treatment of Language”. A Guide to Editing Middle English. Eds. V. P. McCArren and D. MofFAT. Ann Arbor: The University of Michigan Press. 169-183.

Machan, T. W. 1992. "Middle English Text Production and Modern Textual Criticism". Crux and Controversy in Middle English Textual Criticism. Eds. A. J. MinNIs and C. Brewer. Cambridge: D.S. Brewer. 1-18.

MäKInEN, M. 2006. Between Herbals et alia: Intertextuality in Medieval English Herbals. PhD Thesis. Helsinki: University of Helsinki.

Marqués-Aguado, T. 2007. “Old English Punctuation Revisited: The Case of the Gospel according to Saint Matthew”. SELIM Journal 13: 51-72.

. 2008. Edition and Philological Study of G.U.L. MS Hunter 513 (ff. 37v-96v). Unpublished PhD Thesis. Málaga: University of Málaga.

. 2009. "Punctuation Practice in the Antidotary in G.U.L. MS Hunter 513 (ff. 37v-96v)". Miscelánea 39: 55-72.

. 2013. "Editions of Middle English Texts and Linguistic Research: Desiderata regarding Paleography and Editorial Practices". Variants 10: 17-40.

Miranda-García, A. and J. Garrido-Garrido. 2011. Text Search Engine (TexSEn). Málaga: Servicio de Publicaciones de la Universidad de Málaga.

Miranda-García, A. and S. GonZÁLEZ FERnÁNDEZ-Corugedo, eds. 2011. Benvenutus Grassus' On the well-proven art of the eye. Practica Oculorum \& De probatissima arte oculorum. Synoptic Edition and Philological Studies. Vol. 1 of Middle English Texts Series. Frankfurt: Peter Lang.

MirANDA-GARCíA, A. et al., comps. 2007-2011. Málaga Corpus of Late Middle English Scientific Prose. Málaga: University of Málaga. 29 March 2012. <http://hunter. uma.es>.

Moffat, D. 1998. "Making a Glossary". A Guide to Editing Middle English. Eds. V. P. McCarren and D. Moffat. Ann Arbor: The University of Michigan Press. 237-246. 
Moorman, C. 1975. Editing the Middle English Manuscript. Jackson: University Press of Mississippi.

Ogden, M. S., ed. 1971. The Cyrurgie of Guy de Chauliac. vol.1. Vol. 265 of Early English Text Society (Original Series). London/ New York/ Toronto: Oxford University Press.

PARKes, M. B. 1969. English Cursive Book Hands, 1250-1500. Oxford: Clarendon Press.

PetTi, A. G. 1977. English Literary Hands from Chaucer to Dryden. London: Edward Arnold.

Quirk, R. et al. 1992. A Comprehensive Grammar of the English Language. London: Longman.

Simpson, J. A. and E. S. C. WeIner, eds. 2004. The Oxford English Dictionary. Second Edition on CD-ROM. Version 3.1. Oxford: Oxford University Press.

VÁzquez, N. and T. Marqués-Aguado. 2012. "Editing the Medieval Manuscript in its Social Context". The Handbook of Historical Sociolinguistics. Eds. J. M. Hernández-CAmpoy and J. C. Conde-Silvestre. Cambridge: Wiley-Blackwell. 123-139.

Voigts, L. E. 1989. "The Character of the Carecter: Ambiguous Sigils in Scientific and Medical Texts". Latin and Vernacular. Studies in Late-Medieval Texts and Manuscripts. Ed. A. J. Minnis. Cambridge: D.S. Brewer. 91-109.

Voigts, L. E. and P. D. Kurtz. 2000. Scientific and Medical Writings in Old and Middle English: An Electronic Reference (CD-ROM). Michigan: University of Michigan Press.

Young, J. and P. H. Aitken. 1908. A Catalogue of the Manuscripts in the Library of the Hunterian Museum in the University of Glasgow. Planned and Begun by the Late John Young, Continued and Completed by P. Henderson Aitken. Glasgow: Maclehose. 


\section{Please use this identifier to cite or link to this item:}

ht tp://hdl. handle. net/10835/2079

Full metadata record

DC Field

Value

Language

dc.contributor.author Marqués-Aguado, Teresa

dc.date.accessioned 2013-04-04T12: 16:03Z

dc.date.available 2013-04-04T12: 16:03Z

dc.date.issued 2012

dc.identifier.issn 1578-3820

dc.identifier.uri http: // hdl.handle. net/ 10835/2079

dc.description.abstract This article presents the procedure followed es_ES

to carry out the edition of the Antidotary held

in Glasgow, University Library, MS Hunter

513. For the purpose, the treatise is fi rst brie

fl y described, along with its peculiarities;

then, the main dif fi culties encountered

during the transcription process are outlined.

Finally, the features of the printed edition

(including layout, use of critical apparatuses

or of a glossary, etc.) are discussed.

dc.publisher Universidad de Almería.

es_ES

dc.source Odisea : Revista de Estudios Ingleses.

es_ES

Número 13, Enero-Diciembre 2012

dc.subject Middle English

es_ES

dc.subject Editing

es_ES

dc.subject Antidotary

es_ES

dc.subject Paleography

es_ES

dc.subject Scientific texts

es_ES

dc.subject I nglés medio

es_ES

dc.subject Antidotario

es_ES

dc.subject Paleografía

es_ES

dc.subject Textos científicos

es_ES

dc.title From Script to Print: Editing the Antidotary in es_ES Glasgow, University Library, MS Hunter 513

(ff. 37v-96v). 
dc.title.alternative De la escritura a la edición: edición del

es_ES

Antidotario en el manuscrito Glasgow,

University Library, Hunter 513 (fols. 37v-

96v).

dc.type info: eu-repo/semantics/article es_ES

dc.relation.publisherversion http://www.ual.es/odisea/Odisea13_Marques- es_ES

Aguado.pdf

dc.rights.accessRights info: eu-repo/semantics/openAccess

es_ES

Appears in Collections: Odisea : Revista de Estudios Ingleses.

Número 13, Enero-Diciembre 2012 